\title{
Formation of Ti2AuN from Au-Covered Ti2AIN Thin Films: A General Strategy to Thermally Induce Intercalation of Noble Metals into MAX Phases
}

Shun Kashiwaya, Chung-Chuan Lai, Jun Lu, Andrejs Petruhins, Johanna Rosén and Lars Hultman

The self-archived postprint version of this journal article is available at Linköping University Institutional Repository (DiVA):

http://urn.kb.se/resolve?urn=urn:nbn:se:liu:diva-167294

N.B.: When citing this work, cite the original publication.

Kashiwaya, S., Lai, C., Lu, J., Petruhins, A., Rosén, J., Hultman, L., (2020), Formation of Ti2AuN from $\mathrm{Au}$-Covered Ti2AlN Thin Films: A General Strategy to Thermally Induce Intercalation of Noble Metals into MAX Phases, Crystal Growth \& Design, 20(6), 4077-4081.

https://doi.org/10.1021/acs.cgd.oco0355

Original publication available at:

https://doi.org/10.1021/acs.cgd.oc00355

Copyright: American Chemical Society

http://pubs.acs.org/ 


\section{Formation of $\mathrm{Ti}_{2} \mathrm{AuN}$ from $\mathrm{Au}$-covered $\mathrm{Ti}_{2} \mathrm{AlN}$ thin}

\section{films: A general strategy to thermally induce}

\section{intercalation of noble metals into MAX phases}

Shun Kashiwaya*, Chung-Chuan Lai, Jun Lu, Andrejs Petruhins, Johanna Rosen, and Lars

Hultman

Thin Film Physics Division, Department of Physics, Chemistry, and Biology (IFM), Linköping University, SE-581 83 Linköping, Sweden

KEYWORDS: MAX phase, nanolaminated structure, noble metal intercalation

ABSTRACT: Thermally-induced intercalation of noble metals into non-van der Waals ceramic compounds presents a method to produce a new class of layered materials. We recently demonstrated an exchange reaction of Au with A layers of MAX phase carbides with plentiful combinations of $\mathrm{A}$ and $\mathrm{M}$ elements. Here, we report the first substitution of $\mathrm{Al}$ with $\mathrm{Au}$ in a $\mathrm{Ti}_{2} \mathrm{AlN}$ MAX phase nitride at an elevated temperature without destroying the original layered structure. These results bolster the generalization of the Au intercalation for the A elements in MAX phases with diverse combinations of $\mathrm{M}, \mathrm{A}$, and $\mathrm{X}$ elements. Furthermore, we propose crucial factors to achieve the exchange reaction: there should be a chemical potential for the A element to dissolve in or react with noble metals to intercalate; the noble metals should be inert to the initial metal 
carbides/nitrides; and it is necessary to choose the reaction temperature that allows balanced interdiffusion of the noble metals and A elements.

$M_{n+1} A X_{n}$ phases ( $n=1,2$, or 3$)$ are a set of endogenously nanolaminated ternary materials. In this polymorph, $\mathrm{M}_{\mathrm{n}+1} \mathrm{X}_{\mathrm{n}}$ slabs are structurally interleaved with A layers, where $\mathrm{M}$ is a transition metal, A is an element of groups 13-16, and $\mathrm{X}$ is carbon or nitrogen. This particular layered arrangement possesses advantageous chemical and physical properties, which combine characteristics of both metals and ceramics, such as resistance to thermal shock and high thermal and electrical conductivities ${ }^{1,2}$. Of particular interest in recent years are $M_{n+1} A X_{n}$ phases as a precursor to form a newly established class of two-dimensional materials, MXenes; appropriately opted etchants can exfoliate $M_{n+1} A X_{n}$ phases by selectively etching the A layers and leave laminated $\mathrm{M}_{\mathrm{n}+1} \mathrm{X}_{\mathrm{n}}$ terminated with $\mathrm{T}_{\mathrm{n}}$ that stands for surface terminations such as hydroxide and fluorine ${ }^{3,4}$. There are various chemicals and methods used to etch away A elements ${ }^{5}$. The A elements of $M_{n+1} A X_{n}$ phases can also be removed by out-diffusion while reacting with surrounding materials. For example, $\mathrm{Ti}_{3} \mathrm{SiC}_{2}$ thin films are decomposed to amorphous $\mathrm{TiC}_{\mathrm{x}}$ entailing outdiffusion of $\mathrm{Si}$ into deposited $\mathrm{Cu}^{6}, \mathrm{Ni}^{7}, \mathrm{Al}^{8}$, and molten cryolite ${ }^{9}$ at the elevated temperature; therefore, the original layered structures are ruined.

Exchange of the A layers would modify the properties of $M_{n+1} A X_{n}$ phases. We recently demonstrated replacement of $\mathrm{Si}$ as the $\mathrm{A}$ element in $\mathrm{Ti}_{3} \mathrm{SiC}_{2}$ with $\mathrm{Au}$ deposited on the top ${ }^{10}$, which was the pioneering intercalation of noble metals in non-van der Waals solids different to what was conventionally recognized for van der Waals solids ${ }^{11-14}$. Contrary to the above materials forming intermetallic phase with Si that block the interdiffusion of the deposited materials into $\mathrm{Ti}_{3} \mathrm{SiC}_{2}, \mathrm{Au}$ 
forms metastable $\mathrm{Au}-\mathrm{Si}$ silicides that might act as transport phases for interdiffusion of both $\mathrm{Au}$ and $\mathrm{Si}^{15-18}$. Accordingly, vacancies in the $\mathrm{Si}$ layer created by its out-diffusion can be simultaneously back-filled with $\mathrm{Au}$ atoms. The resulting $\mathrm{Ti}_{3} \mathrm{AuC}_{2}$ showed remarkable thermal stability and functioned as a stable ohmic electrical contact to a $\mathrm{SiC}$ substrate in harsh oxidizing environments. Starting with $\mathrm{Ti}_{3} \mathrm{SiC}_{2}$ as the model case, the substitutional intercalation of Au with A elements in $M_{n+1} A X_{n}$ phases was achieved using $T_{n+1} A_{C} C_{n}(n=1 \text { and } 2)^{19}, M_{2} G a_{n} C(n=1$ and 2) $)^{20}$, and $\left(\mathrm{Cr}_{0.5} \mathrm{Mn}_{0.5}\right)_{2} \mathrm{GaC}^{21}$ while the layered structures of these $\mathrm{M}_{\mathrm{n}+1} \mathrm{AX}$ phases remained in the resulting compounds. This suggests a generalization of the substitutional reaction for at least $\mathrm{M}_{n+1} A X_{n}$ phase carbides with a possible additional combination of $M$ and $A$ elements hitherto unexplored.

To clarify whether the substitutional intercalation of $\mathrm{Au}$ is comprehensively operational for $M_{n+1} A X_{n}$ phases, the Au substitution reaction should be examined also for $M_{n+1} A X_{n}$ phase nitrides $(X=N)$, for which intercalation of noble metals has not been realized. Due to an additional valence electron in $\mathrm{N}$ compared to $\mathrm{C}$ and thus its larger electronegativity than $\mathrm{C}$, nitrides and carbides are fundamentally different in terms of properties of their bonding ${ }^{22}$. Furthermore, MAX phase nitrides and carbides show distinct differences in the distribution of the density of states ${ }^{23}$. Thus, the electronic and electrical conductivity/resistivity properties of MAX phases differ significantly between the two types of ceramics. Therefore, it is of importance to test the intercalation of $\mathrm{Au}$ into both MAX phases to establish any universality of the substitutional reaction. An attractive candidate for such attempts is $\mathrm{Ti}_{2} \mathrm{AlN}$ owing to its superior electrical conductivity compared with $\mathrm{Ti}_{2} \mathrm{AlC}$ of the carbide counterpart ${ }^{24-26}$ as $\mathrm{Ti}_{3} \mathrm{AlN}_{2}$ has not been realized ${ }^{27}$. While the electrical conductivity of $\mathrm{Ti}_{2} \mathrm{AuN}$ has not yet been possible to measure, due to the prevailing condition of retained unreacted $\mathrm{Ti}_{2} \mathrm{AlN}$ parts, the intercalation of noble metals 
into $\mathrm{Ti}_{2} \mathrm{AlN}$ would be expected to enhance its thermal stability of relevance to electronic applications.

In that context, we here report on the formation of a new nanolaminated thin film of $\mathrm{Ti}_{2} \mathrm{AuN}$ by replacing $\mathrm{Al}$ with $\mathrm{Au}$ in $\mathrm{Ti}_{2} \mathrm{AlN}$ via thermally induced intercalation. This is the first time that the substitutional intercalation of $\mathrm{Au}$ in $\mathrm{M}_{\mathrm{n}+1} \mathrm{AX}$ phase nitrides has been demonstrated. Furthermore, we discuss crucial factors for this phenomenon: sufficient solubility or reactivity of such noble metal with the original A element and stability of the $M_{n+1} X_{n}$ sublayers against the noble metal incorporated into $M_{n+1} A X_{n}$ phases.

$\mathrm{Ti}_{2} \mathrm{AlN}$ was grown on c-plane sapphire (001) substrates by using direct current magnetron sputter(DCMS) deposition from metallic targets of Ti and Al. The deposition was performed under a $\mathrm{N}_{2} / \mathrm{Ar}$ mixture atmosphere at a total deposition pressure of $3 \mathrm{mTorr}$. The gas flow ratio of $\mathrm{N}_{2} / \mathrm{Ar}$ was kept at 1/20. The applied power for Ti and Al targets was 300 and $100 \mathrm{~W}$, respectively. The $\mathrm{Al}$ and $\mathrm{Ti}$ targets were placed to the substrate perpendicularly and at a $35^{\circ}$ angle tilted off the substrate normal, respectively. The substrates were heated up to $1173 \mathrm{~K}$ prior to deposition at a rate of $30 \mathrm{~K} / \mathrm{min}$. The base pressure was kept at $10^{-8}$ Torr in the chamber. More details of the deposition system and the experimental approach may be found elsewhere ${ }^{28}$.

The deposited $\mathrm{Ti}_{2} \mathrm{AlN}$ thin films were etched in buffered $\mathrm{HF}\left(\mathrm{NH}_{3} \mathrm{~F}(25 \mathrm{~g})+\mathrm{H}_{2} \mathrm{O}(50 \mathrm{ml})\right.$ $+\mathrm{HF}(10 \mathrm{ml}))$ for $5 \mathrm{~s}$ to remove residual oxides on the surface and immediately transferred into the other deposition chamber with a base pressure of $\sim 1 \times 10^{-10}$ Torr. The films were covered with $\mathrm{Au}$ to a thickness of $500 \mathrm{~nm}$ using DCMS from a Au target placed at $20 \mathrm{~cm}$ above the sample and $20^{\circ}$ tilted away from the sample. The Au-covered samples were transferred into a quartz tube inserted in a tube furnace for annealing at $673 \mathrm{~K}$ for $5 \mathrm{~h}$ and subsequently at $773 \mathrm{~K}$ for $6 \mathrm{~h}$. The 
furnace was heated up at a ramping rate of $\sim 18 \mathrm{~K} / \mathrm{min}$. To avoid oxidation of the samples, nitrogen gas was flowing through the quartz tube for $2 \mathrm{~h}$ before and during annealing.

The phase composition of the samples was identified from X-ray diffraction (XRD) patterns, acquired by a Philips PW 1820 diffractometer using $\mathrm{Cu} \mathrm{K} \alpha$ radiation. Scanning electron microscopy (SEM) was performed in a LEO 1550 for imaging and energy dispersive X-ray analysis (EDX) of the surface. Structural analysis was carried out by high-resolution STEM high angle annular dark field (HRSTEM-HAADF) imaging within Linköping's double $\mathrm{C}_{\mathrm{S}}$ corrected FEI $\operatorname{Titan}^{3}$ 60-300 microscope operated at $300 \mathrm{kV}$. HRSTEM-HAADF imaging was performed using $21.5 \mathrm{mrad}$ probe convergence angle. The corresponding cross-sectional samples were mechanically polished to a thickness of about $60 \mu \mathrm{m}$, followed by ion-beam milling with $\mathrm{Ar}^{+}$in a Gatan precision ion polishing system at $5 \mathrm{keV}$ with a final polishing step at $1 \mathrm{keV}$ of ion energy.

We studied the surface and bulk composition of the Au-deposited $\mathrm{Ti}_{2} \mathrm{AlN}$ film after annealing. Figure 1 shows the SEM/EDX analysis of the sample, where Al islands have formed on the $\mathrm{Au}$ surface. $\mathrm{Al}$ from the $\mathrm{A}$ layer separating $\mathrm{Ti}_{2} \mathrm{~N}$ was diffused out into the deposited $\mathrm{Au}$ layer similar to previously reported cases of the $A u$ intercalation into other $M_{n+1} A X_{n}$ phase carbides with $\mathrm{A}=\mathrm{Si}, \mathrm{Al}$, and $\mathrm{Ga}^{10,19-21}$. Interdiffusion between $\mathrm{Au}$ and $\mathrm{Al}$ is active at our annealing temperature ${ }^{29,30}$. Moreover, $\mathrm{Al}$ atoms are loosely bonded to $\mathrm{Ti}$ in the $\mathrm{Ti}_{2} \mathrm{AlN}$ crystal. Thus, in the presence of $\mathrm{Au}$ covering $\mathrm{Al}$, the diffusion of $\mathrm{Al}$ into $\mathrm{Au}$ occurs as $\mathrm{Al}$ atoms have a lower chemical potential in an $\mathrm{Au}$ reservoir than in the $\mathrm{Ti}_{2} \mathrm{AlN}$ crystal. As a result, at the appropriately selected temperature $\mathrm{Al}$ can more or less completely segregate to the surface through the top Au layer, as shown in Figure 1, without ruining the layered structure of the MAX phase. Figure 2 shows HRSTEM images of annealed Au-deposited $\mathrm{Ti}_{2} \mathrm{AlN}$ acquired along the zone axes [11 $\left.\overline{2} 0\right]$ and [1100]. The brightness in the STEM is proportional to the mass of atoms through which a beam 
of electrons is transmitted. The atomic arrangements correspond to those of a $\mathrm{M}_{2} \mathrm{AX}$ phase: the typical laminar structure comprised of layers of a heavy element, $\mathrm{Au}$, alternating $\mathrm{Ti}_{2} \mathrm{~N}$ layers. Each $\mathrm{Ti}_{2} \mathrm{~N}$ sheet is stacked on one another with a zig-zag pattern sandwiched by Au monolayers. This evidently means that out-diffusion of $\mathrm{Al}$ induced by the elevated temperature occurs with indiffusion of Au without destroying the original layered structure.
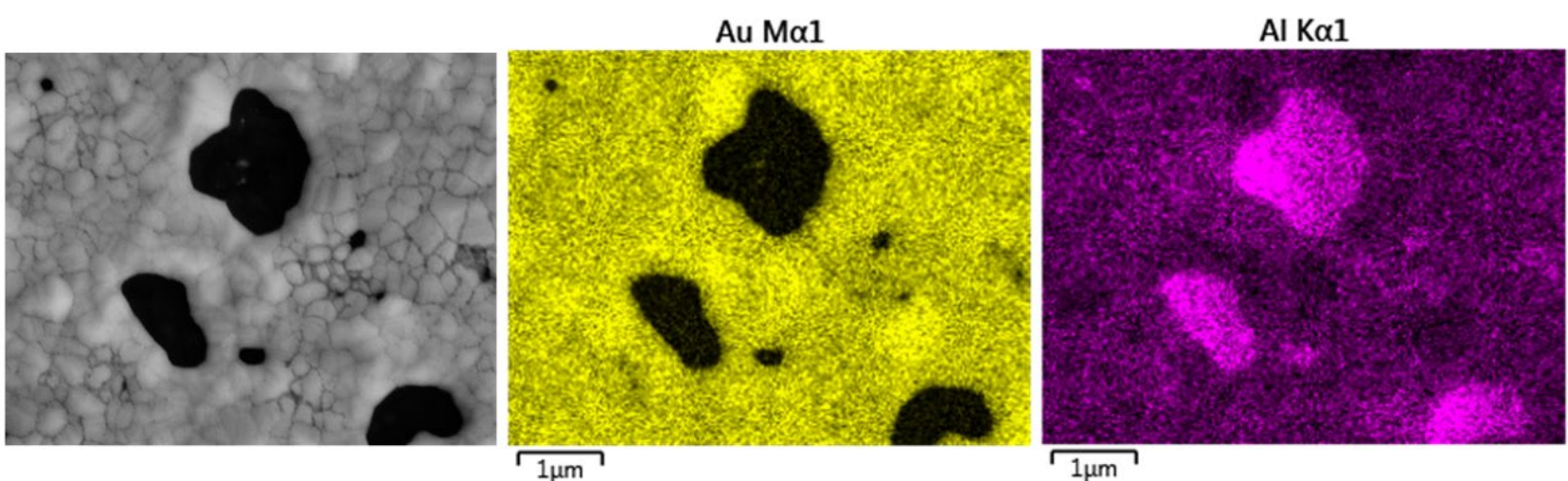

Figure 1. The SEM image (left) and elemental mapping of the surface of annealed Au-deposited Ti $2 \mathrm{AlN}$ : $\mathrm{Au}$ (center) and $\mathrm{Al}$ (right).

a)

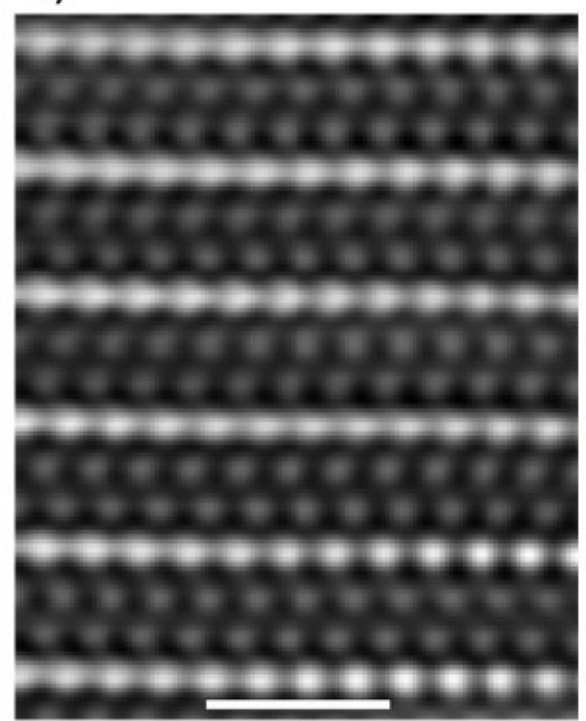

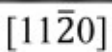

b)

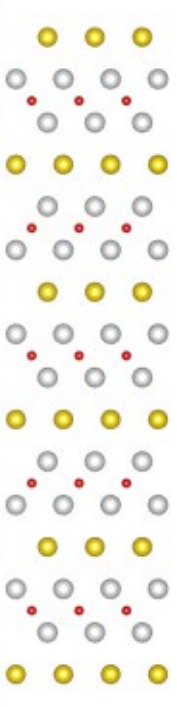

$\circ \circ \circ$

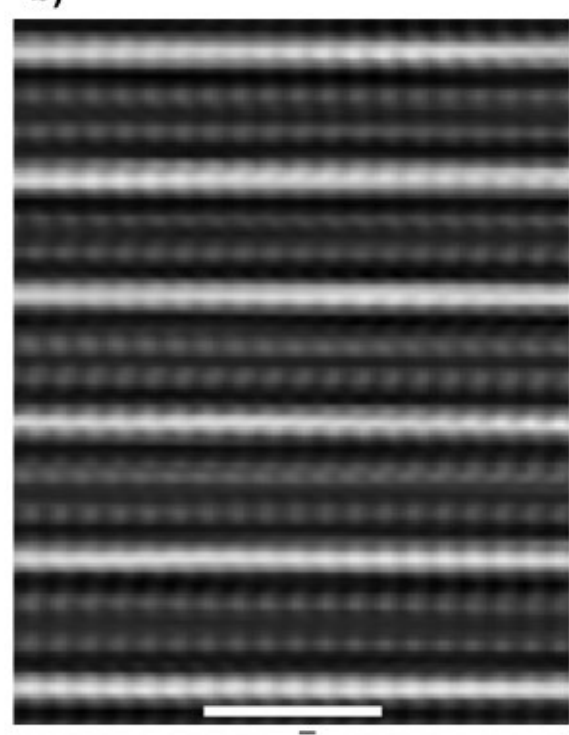

[11̄00]

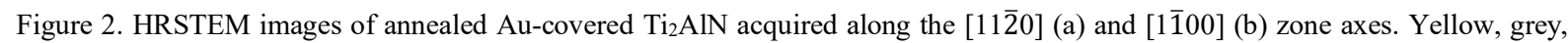
and red balls represent $\mathrm{Au}, \mathrm{Ti}$, and $\mathrm{N}$ atoms, respectively, revealing $\mathrm{Ti}_{2} \mathrm{AuN}$ formation. Scale bars, $1 \mathrm{~nm}$. 
To get a deeper understanding of the crystal structure, we performed HRSTEM and XRD for the prepared samples. According to a line profile of the HRSTEM images analyzed by GMS3 software, the c lattice parameter expands upon the Al-Au exchange from $13.66^{31}$ to $14.05 \AA$. Figure 3 shows the XRD patterns for the samples before and after Au infusion. Diffraction peaks at about 13 and $26^{\circ}$ correspond to $(0002)$ and $(0004)$ of $\mathrm{Ti}_{2} \mathrm{AlN}$, respectively. The peak appearing at about $28^{\circ}$ after annealing is attributed to Al-Au intermetallic phases of $\mathrm{AlAu}_{4}$ formed on top of samples due to diffusion of $\mathrm{Al}$ into $\mathrm{Au}$ as shown in Figure $1^{29}$. It is known that at the elevated temperature, various intermetallic phases are formed as a result of interdiffusion between $\mathrm{Au}$ and $\mathrm{Al}: \mathrm{Al}_{2} \mathrm{Au}$, $\mathrm{AlAu}, \mathrm{AlAu}_{2}, \mathrm{Al}_{2} \mathrm{Au}_{5}$, and $\mathrm{AlAu}_{4}{ }^{32} . \mathrm{Al}_{2} \mathrm{Au}_{5}$ was found to be initially a predominant phase at 733 $\mathrm{K}$ close to our annealing temperature of $773 \mathrm{~K}$. However, it was reported that unstable $\mathrm{Al}_{2} \mathrm{Au}_{5}$ rapidly transformed into $\mathrm{AlAu}_{4}$ at a lower temperature of $673 \mathrm{~K}^{29}$. In this work, $\mathrm{Al}_{2} \mathrm{Au}_{5}$, which would form at our annealing temperature, might be transformed into $\mathrm{AlAu}_{4}$ during cooling. Therefore, the identical diffraction peak of $\mathrm{Al}_{2} \mathrm{Au}_{5}$ does not appear in Figure 3. The Au-exchange reaction resulted in slightly broadening $(000 l)$ peaks. This expansion would correspond to residuals of $\mathrm{Ti}_{2} \mathrm{AlN}$ and $\mathrm{Ti}_{2} \mathrm{AuN}$. The MAX crystal structure is preserved during the Au-exchange reaction, where HRSTEM images reveal a lattice expansion by $2.9 \%$ corresponding to a theoretical shift of the (0004) diffraction peak by $0.71^{\circ 33}$. Due to such a slight shift, the diffraction peaks of $(000 l)$ seem to get broadened after annealing; for example, for (0004) the original FWHM of $0.31^{\circ}$ was increased by $0.35^{\circ}$. The overlapping peaks also imply that the A atom exchange was not completed for the duration of the annealing experiment as there is some retained $\mathrm{Ti}_{2} \mathrm{AlN}$ phase. For the case of the intercalation of $\mathrm{Au}$ into $\mathrm{Ti}_{3} \mathrm{SiC}_{2}$, the substitution of $\mathrm{Si}$ with $\mathrm{Au}$ takes place from the top surface of $\mathrm{Ti}_{3} \mathrm{SiC}_{2}$ toward the substrate layer by layer ${ }^{10}$. We thus expect the substitutional reaction 
occurs for $\mathrm{Ti}_{2} \mathrm{AuN}$ in the same manner and annealing it longer, therefore, would complete the exchange.

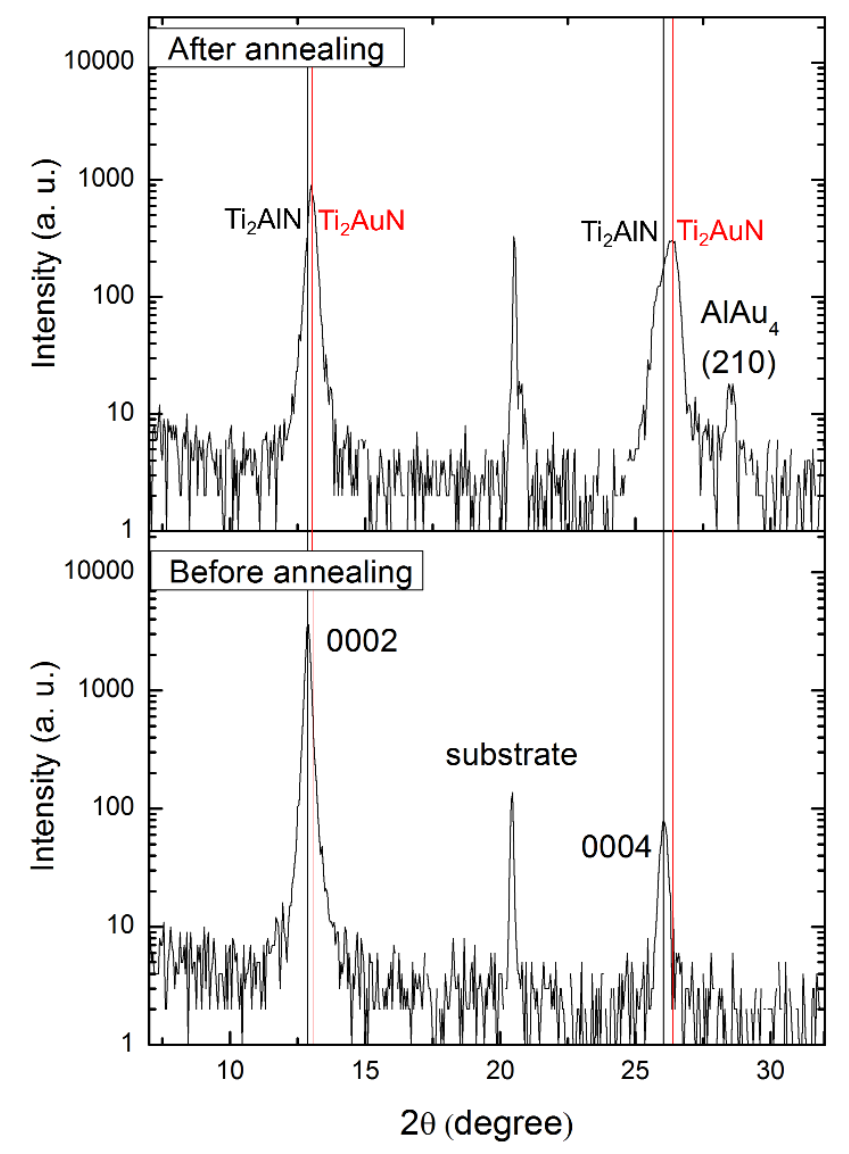

Figure 3. XRD patterns of Au-covered $\mathrm{Ti}_{2} \mathrm{AlN}$ before and after annealing.

These results verify the assumption that the replacement of $\mathrm{Al}$ with $\mathrm{Au}$ would be triggered by out-diffusion of $\mathrm{Al}$ along with simultaneous in-diffusion of $\mathrm{Au}$, which compensates for the formed $\mathrm{Al}$ vacancies to preserve the original structure of the $\mathrm{M}_{2} \mathrm{AX}$ phase nitride. Herein, we thus generalize the strategy to intercalate noble metals into $M_{n+1} A X_{n}$ phases by expanding the sets of combinations of $\mathrm{M}, \mathrm{A}$, and $\mathrm{X}$ elements. As proposed previously ${ }^{20}$, the Au-exchange reaction takes 
place between $A u$ atoms capping the $M_{n+1} A X_{n}$ phase and original $A$ atoms of the $M_{n+1} A X_{n}$ phase with the two-step process: (1) introducing vacancies in the A layers by diffusion of the A elements and (2) subsequent backfilling the vacancies with a new intercalated element, denoted as A'.

To trigger the massive replacement of A with A', A' has to introduce instability in the bonding of A adjacent to A' at the interface. There should be a chemical potential for the A element to dissolve in or react with noble metals; in addition, the MX layered structure has to be stable against the diffusion of both $\mathrm{A}$ and $\mathrm{A}^{\prime}$ atoms through the layers. For example, at the annealing temperature of this work, TiN is stable in the presence of various metals surrounding TiN, including $\mathrm{Au}^{34,35}$, so that the intercalation of $\mathrm{Au}$ into $\mathrm{Ti}_{2} \mathrm{AlN}$ introduces no transformation of the original layered structure. On the other hand, deposited $\mathrm{Cu}^{6}, \mathrm{Ni}^{7}, \mathrm{Al}^{8}$, and molten cryolite ${ }^{9}$ destroys the layered $\mathrm{Ti}_{3} \mathrm{C}_{2}$ of $\mathrm{Ti}_{3} \mathrm{SiC}_{2}$ into amorphous $\mathrm{TiC}_{\mathrm{x}}$ at the elevated temperature; therefore, the intercalation of these elements is ruled out. This is opposed to Au, which causes no critical instability of the structure of $\mathrm{Ti}_{3} \mathrm{C}_{2}$. In this work, $\mathrm{Al}$ and $\mathrm{Au}$ formed $\mathrm{AlAu}_{4}$. However, due to the preponderance of gold-rich phases such as $\mathrm{Al}_{2} \mathrm{Au}_{5}$ and $\mathrm{AlAu}_{4}$, the intermetallic layers are prone to grow into $\mathrm{Au}$ at the top interface ${ }^{30}$. Thus, the balanced interdiffusion between $\mathrm{Al}$ and $\mathrm{Au}$ can take place without damaging the structure of the $M_{n+1} A X_{n}$ phase despite the formation of intermetallic phases. By aptly selecting the A-A' combination and annealing temperature, intercalation of A' into $M_{n+1} A X_{n}$ phases would be universally operational, where $A^{\prime}$ is not only limited to experimentally realized Au intercalation but also for other noble metals.

In conclusion, we demonstrate that thermally-induced intercalation of $\mathrm{Au}$ into $\mathrm{Ti}_{2} \mathrm{AlN}$ can be used to form $\mathrm{Ti}_{2} \mathrm{AuN}$ as a noble phase. We also discuss the mechanism of the exchange reaction of noble metals and A layers and propose key factors for the corresponding reaction. A' should exhibit negative heat of mixing with A at the annealing temperature; the layered structure of the 
original $\mathrm{M}_{\mathrm{n}+1} \mathrm{AX}_{\mathrm{n}}$ should be stable against the exchanged elements; and the appropriate temperature of annealing has to be selected to meet all the above requirements. Our results bolster the generality of the intercalation process for $\mathrm{M}_{n+1} \mathrm{AX}_{\mathrm{n}}$ phases to plentiful combinations of comprising $\mathrm{M}, \mathrm{A}$, and $\mathrm{X}$ elements. They also pave a strategy to explore the new class of layered transition metal carbides/nitrides with tailored chemical and physical properties. Furthermore, this strategy should be envisioned to intercalate noble metals into not only thin films of $M_{n+1} A X_{n}$ phases but also corresponding bulk or particulate $M_{n+1} A X_{n}$ phases.

\section{AUTHOR INFORMATION}

\section{Corresponding Author}

*Shun Kashiwaya - Email: shun.kashiwaya@liu.se

\section{Author Contributions}

S.K. and C.L. designed the experiments and analyzed the data. S.K. wrote the manuscript, with input from all co-authors. S.K., C.L., A.P., and J.L. performed the experiments. L.H. and J.R. supervised the project.

\section{Notes}

The authors declare no competing financial interest.

\section{ACKNOWLEDGMENT}

L.H. and J.R. acknowledge the Swedish Research Council through the project grants 2017-03909 and 642-2013-8020, and the Knut and Alice Wallenberg (KAW) Foundation foundation for scholarship grants as well as for support to the Linköping Electron Microscopy Laboratory. J.R. 
also acknowledges support from the Swedish Foundation for Strategic Research (SSF) for a program grant (EM16-0004).

\section{ABBREVIATIONS}

DCMS, direct current magnetron sputter; XRD, X-ray diffraction; SEM, Scanning electron microscopy; HRSTEM-HAADF, high-resolution scanning transmission electron microscopy high angle annular dark field.

\section{REFERENCES}

1. Barsoum, M. W., The $\mathrm{M}_{\mathrm{N}+1} \mathrm{AX}_{\mathrm{N}}$ phases: A new class of solids: Thermodynamically stable nanolaminates. Prog. Solid State Chem. 2000, 28, 201-281.

2. Eklund, P.; Rosen, J.; Persson, P. O. Å., Layered ternary $\mathrm{M}_{\mathrm{N}+1} \mathrm{AX}_{\mathrm{N}}$ phases and their 2D derivative MXene: an overview from a thin-film perspective. J. Phys. D: Appl. Phys. 2017, 50, 113001.

3. Anasori, B.; Lukatskaya, M. R.; Gogotsi, Y., 2D metal carbides and nitrides (MXenes) for energy storage. Nat. Rev. Mater. 2017, 2, 16098.

4. Naguib, M.; Kurtoglu, M.; Presser, V.; Lu, J.; Niu, J.; Heon, M.; Hultman, L.; Gogotsi, Y.; Barsoum, M. W., Two-dimensional nanocrystals produced by exfoliation of $\mathrm{Ti}_{3} \mathrm{AlC}_{2}$. Adv. Mater. 2011, 23, 4248-4253.

5. Verger, L.; Natu, V.; Carey, M.; Barsoum, M. W., MXenes: An Introduction of Their Synthesis, Select Properties, and Applications. Trends Chem. 2019, 1, 656-669.

6. Zhou, Y.; Gu, W., Chemical reaction and stability of $\mathrm{Ti}_{3} \mathrm{SiC}_{2}$ in $\mathrm{Cu}$ during hightemperature processing of $\mathrm{Cu} / \mathrm{Ti}_{3} \mathrm{SiC}_{2}$ composites. Z. Metallkd. 2004, 95, 50-56. 
7. Yin, X.; Li, M.; Zhou, Y., Microstructure and mechanical strength of diffusion-bonded $\mathrm{Ti}_{3} \mathrm{SiC}_{2} / \mathrm{Ni}$ joints. J. Mater. Res. 2006, 21, 2415-2421.

8. El-Raghy, T.; Barsoum, M.; Sika, M., Reaction of $\mathrm{Al}$ with $\mathrm{Ti}_{3} \mathrm{SiC}_{2}$ in the $800-1000^{\circ} \mathrm{C}$ temperature range. Mater. Sci. Eng., A 2001, 298, 174-178.

9. Barsoum, M. W.; El-Raghy, T.; Farber, L.; Amer, M.; Christini, R.; Adams, A., The Topotactic Transformation of Ti3SiC2 into a Partially Ordered Cubic $\mathrm{Ti}\left(\mathrm{C}_{0.67} \mathrm{Si}_{0.06}\right)$ Phase by the Diffusion of Si into Molten Cryolite. J. Electrochem. Soc. 1999, 146, 3919-3923.

10. Fashandi, H.; Dahlqvist, M.; Lu, J.; Palisaitis, J.; Simak, S. I.; Abrikosov, I. A.; Rosen, J.; Hultman, L.; Andersson, M.; Spetz, A. L., Synthesis of $\mathrm{Ti}_{3} \mathrm{AuC}_{2}, \mathrm{Ti}_{3} \mathrm{Au}_{2} \mathrm{C}_{2}$ and $\mathrm{Ti}_{3} \mathrm{IrC}_{2}$ by noble metal substitution reaction in $\mathrm{Ti}_{3} \mathrm{SiC}_{2}$ for high-temperature-stable Ohmic contacts to SiC. Nat. Mater. 2017, 16, 814 .

11. Whittingham, M. S., Chemistry of intercalation compounds: metal guests in chalcogenide hosts. Prog. Solid State Chem. 1978, 12, 41-99.

12. Van der Ven, A.; Bhattacharya, J.; Belak, A. A., Understanding Li diffusion in Liintercalation compounds. Acc. Chem. Res. 2012, 46, 1216-1225.

13. Koski, K. J.; Cha, J. J.; Reed, B. W.; Wessells, C. D.; Kong, D.; Cui, Y., High-density chemical intercalation of zero-valent copper into $\mathrm{Bi}_{2} \mathrm{Se}_{3}$ nanoribbons. J. Am. Chem. Soc. 2012, $134,7584-7587$. 
14. Yao, J.; Koski, K. J.; Luo, W.; Cha, J. J.; Hu, L.; Kong, D.; Narasimhan, V. K.; Huo, K.; Cui, Y., Optical transmission enhacement through chemically tuned two-dimensional bismuth chalcogenide nanoplates. Nat. Commun. 2014, 5, 5670.

15. Tu, K., Selective growth of metal-rich silicide of near-noble metals. Appl. Phys. Lett. $1975,27,221-224$.

16. Hiraki, A.; Lugujjo, E.; Mayer, J. W., Formation of silicon oxide over gold layers on silicon substrates. J. Appl. Phys. 1972, 43, 3643-3649.

17. Lee, S.-H.; Stephens, J. A.; Hwang, G. S., On the nature and origin of Si surface segregation in amorphous AuSi alloys. J. Phys. Chem. C 2010, 114, 3037-3041.

18. Okamoto, H.; Massalski, T., The Au-Si (gold-silicon) system. Bull. Alloy Phase Diagrams 1983, 4, 190-198.

19. Fashandi, H.; Lai, C.-C.; Dahlqvist, M.; Lu, J.; Rosen, J.; Hultman, L.; Greczynski, G.; Andersson, M.; Spetz, A. L.; Eklund, P., $\mathrm{Ti}_{2} \mathrm{Au}_{2} \mathrm{C}$ and $\mathrm{Ti}_{3} \mathrm{Au}_{2} \mathrm{C}_{2}$ formed by solid state reaction of gold with $\mathrm{Ti}_{2} \mathrm{AlC}$ and $\mathrm{Ti}_{3} \mathrm{AlC}_{2}$. ChemComm 2017, 53, 9554-9557.

20. Lai, C.-C.; Fashandi, H.; Lu, J.; Palisaitis, J.; Persson, P. O.; Hultman, L.; Eklund, P.; Rosen, J., Phase formation of nanolaminated $\mathrm{Mo}_{2} \mathrm{AuC}$ and $\mathrm{Mo}_{2}\left(\mathrm{Au}_{1-\mathrm{x}} \mathrm{Ga}_{\mathrm{x}}\right)_{2} \mathrm{C}$ by a substitutional reaction within $\mathrm{Au}$-capped $\mathrm{Mo}_{2} \mathrm{GaC}$ and $\mathrm{Mo}_{2} \mathrm{Ga}_{2} \mathrm{C}$ thin films. Nanoscale 2017, 9, 17681-17687.

21. Lai, C.-C.; Tao, Q.; Fashandi, H.; Wiedwald, U.; Salikhov, R.; Farle, M.; Petruhins, A.; Lu, J.; Hultman, L.; Eklund, P.; Rosen, J. Magnetic properties and structural 
characterization of layered $\left(\mathrm{Cr}_{0.5} \mathrm{Mn}_{0.5}\right)_{2} \mathrm{AuC}$ synthesized by thermally induced substitutional reaction in $\left(\mathrm{Cr}_{0.5} \mathrm{Mn}_{0.5}\right)_{2} \mathrm{GaC}$. APL Mater. 2018, 6, 026104.

22. Schwarz, K., Band structure and chemical bonding in transition metal carbides and nitrides. Crit. Rev. Solid State Mater. Sci. 1987, 13, 211-257.

23. Magnuson, M.; Mattesini, M.; Li, S.; Höglund, C.; Beckers, M.; Hultman, L.; Eriksson, O., Bonding mechanism in the nitrides $\mathrm{Ti}_{2} \mathrm{Al} \mathrm{N}$ and TiN: An experimental and theoretical investigation. Phys. Rev. B 2007, 76, 195127.

24. Hug, G.; Fries, E., Full-potential electronic structure of Ti $2{ }_{2} \mathrm{AlC}$ and Ti $2 \mathrm{AlN}$. Phys. Rev. $B$ 2002, 65, 113104.

25. Haddad, N.; Garcia-Caurel, E.; Hultman, L.; Barsoum, M. W.; Hug, G., Dielectric properties of $\mathrm{Ti}_{2} \mathrm{AlC}$ and $\mathrm{Ti}_{2} \mathrm{AlN}$ MAX phases: The conductivity anisotropy. J. Appl. Phys 2008, 104, 023531.

26. Barsoum, M.; El-Raghy, T.; Ali, M., Processing and characterization of $\mathrm{Ti}_{2} \mathrm{AlC}, \mathrm{Ti}_{2} \mathrm{AlN}$, and $\mathrm{Ti}_{2} \mathrm{AlC}_{0.5} \mathrm{~N}_{0.5}$. Metall. Mater. Trans. A 2000, 31, 1857-1865.

27. Eklund, P.; Beckers, M.; Jansson, U.; Högberg, H.; Hultman, L., The $\mathrm{M}_{\mathrm{n}+1} \mathrm{AX}$ n phases: Materials science and thin-film processing. Thin Solid Films 2010, 518, 1851-1878.

28. Fashandi, H.; Andersson, M.; Eriksson, J.; Lu, J.; Smedfors, K.; Zetterling, C.-M.; Spetz, A. L.; Eklund, P., Single-step synthesis process of $\mathrm{Ti}_{3} \mathrm{SiC}_{2}$ ohmic contacts on $4 \mathrm{H}-\mathrm{SiC}$ by sputter-deposition of Ti. Scr. Mater. 2015, 99, 53-56. 
29. Kizaki, Y.; Mori, M.; Saito, M. In Development of Au-Al solid phase diffusion flip chip bonding, Proceedings of 1995 Japan International Electronic Manufacturing Technology Symposium, IEEE: 1995; pp 105-108.

30. Philofsky, E. In Purple plague revisited, 8th Reliability Physics Symposium, IEEE: 1970; pp 177-185.

31. Persson, K., Materials Data on $\mathrm{Ti}_{2} \mathrm{AlN}$ (SG:194) by Materials Project. ; LBNL Materials Project; Lawrence Berkeley National Lab. (LBNL), Berkeley, CA (United States): 2016.

32. Predel, B., Al-Au (Aluminum-Gold). In $A c-A u-A u-Z r$, Springer: 1991; pp 1-8.

33. Cullity, B. D., Elements of X-ray Diffraction. 2001.

34. Musher, J. N.; Gordon, R. G., Low-temperature CVD TiN as a diffusion barrier between gold and silicon. J. Electron. Mater. 1991, 20, 1105-1107.

35. Mühlbacher, M.; Greczynski, G.; Sartory, B.; Mendez-Martin, F.; Schalk, N.; Lu, J.; Hultman, L.; Mitterer, C., TiN diffusion barrier failure by the formation of $\mathrm{Cu}_{3} \mathrm{Si}$ investigated by electron microscopy and atom probe tomography. J. Vac. Sci. Technol., B: Nanotechnol.

Microelectron.: Mater., Process., Meas., Phenom. 2016, 34, 022202. 


\section{Formation of $\mathrm{Ti}_{2} \mathrm{AuN}$ from Au-covered $\mathrm{Ti}_{2} \mathrm{AlN}$ thin}

\section{films: A general strategy to thermally induce}

\section{intercalation of noble metals into MAX phases}

Shun Kashiwaya*, Chung-Chuan Lai, Jun Lu, Andrejs Petruhins, Johanna Rosen, and Lars Hultman

Table of Contents graphic

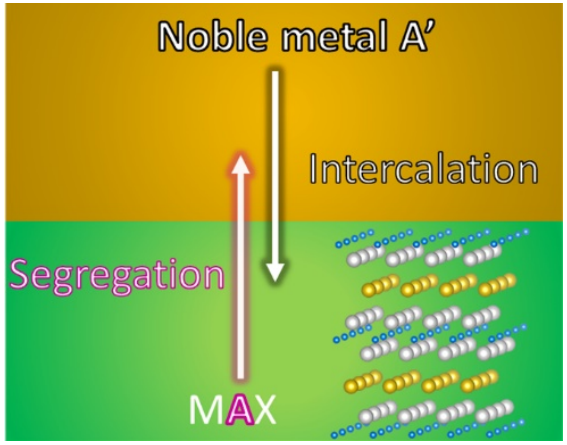

SYNOPSIS: Thermally-induced intercalation of noble metals into non-van der Waals ceramic compounds presents a method to produce a new class of layered materials. Here, we report the first substitution of $\mathrm{Al}$ with $\mathrm{Au}$ in a $\mathrm{Ti}_{2} \mathrm{AlN}$ MAX phase nitride at an elevated temperature without destroying the original layered structure. These results bolster the generalization of the $\mathrm{Au}$ intercalation for the A elements in MAX phases with diverse combinations of $\mathrm{M}, \mathrm{A}$, and $\mathrm{X}$ elements. 